\title{
Recycling Waste Fabrics to Sanitize the Nigerian Environment
}

\author{
Chidume, E. U. \\ Department of Fashion Design \& Clothing Technology \\ Delta State Polytechnic \\ Ogwashi-Uku, Delta State, Nigeria \\ E-mail: centurydoveuchec@gmail.com
}

\begin{abstract}
The study is an opinion paper which started by explaining the concepts of recycling, wastes, and fabrics. It also identified different sources of waste fabrics to include industrial mistakes, pattern marker fallouts, marker making fall outs, remnants from free hand cutting, old clothes from homes, damages from factories, spreading losses, and tailors mistakes. Uses of these waste fabrics were also noted to include sewing new clothes, making bed sheets and quilts, making new bags, making and foot wears. The economic importances of these articles from waste fabrics were also identified to include profit making, entrepreneurship training, production of instructional materials and environmental sanitation. Conclusions and recommendations were also made based on the study.
\end{abstract}

Keywords: Energy recovery, Gasification, Incineration, Landfill, Material recovery, Waste

Aims Research Journal Reference Format:

Chidume, E. U. (2018): Recycling Waste Fabrics to Sanitize the Nigerian Environment. Advances in Multidisciplinary \& Scientific Research Journal. Vol. 4. No.1, Pp29-34

\section{INTRODUCTION}

Recycling is the process of converting waste materials into new materials and objects (Wikipedia 2018). It is an alternative to "conventional" waste disposal that can save material and help lower greenhouse emissions. Recycling can prevent the waste of potentially useful materials and reduce the consumption of fresh raw materials, thereby reducing energy usage, air pollution and water pollution. Wikipedia (2018) also added that recycling is a key component of modern waste reduction. Recyclable materials include many kinds of glass, paper and cardboard, metal, plastic, tires, textiles, electronics, among others. Materials to be recycled are either brought to a collection centre or picked up from the road sides, then sorted, cleaned, and reprocessed into new materials. According to Wikipedia (2018) recycling of a material would produce a fresh supply of the same material. This means that recycling involves the conversion of wastes into reusable materials. With this, recycling is the process of converting waste materials into new materials and objects. This made Rouse (2018) to emphasize that recycling is the process of reusing things that would otherwise be discarded as wastes.

Wastes are unwanted or unusable materials, substances, or by-products. Waste is any substance which is discarded after primary use, or it is worthless, defective and of no use (Wikipedia 2018). American Veterinary Medical Association (2018) also stated that waste is everything that no longer has a use or purpose and needs to be disposed of. Waste can be classified into five types which are all commonly found around the house. These include liquid waste, solid rubbish, organic waste, recyclable rubbish and hazardous waste. About half of collected used clothing are reusable as second hand clothes (FCC Austria Abfall Service AG 2018), as long as the textile used in making the clothing has not deteriorated beyond repairs.

Textiles are fabrics and they typically make up clothing or accessories (Teracycle 2018). According to Anomie (2018), a textile is a flexible material consisting of a network of natural or artificial fibres. Encarta (2009) added that textiles are raw materials like fibre or yarn used for making fabrics. Yarn is produced by spinning raw fibres of wool, flax, cotton, hemp, or other materials to produce long strands of textiles. Anomie (2018) pointed out that the words fabric and cloth are often used in textile assembly trades (such as tailoring and dressmaking) as synonyms for textile. Since Clayton (2000) stated that fibres are tiny strands that make up yarns, textiles are therefore cloth or fabric that is woven, knitted, or otherwise manufactured. Textiles are used to make up clothing. Clothing which means a covering for something can also be called clothes in a collective sense. However there are subtle differences in these terms in specialised usage. A textile is any material made of interlacing fibres; a fabric is a material made through weaving, knitting, spreading, crocheting, or bonding and these may be used in the production of further goods while a cloth may be used synonymously with fabric but it is often a piece of fabric that has been processed (Anomie 2018). 
Fabrics have an assortment of uses, the most common of which are for clothing and for containers such as bags and baskets. In the household they are used in carpeting, upholstered furnishing, window shades, towels, coverings for tables, beds and other flat surfaces (Anomie 2018). Fabrics are used in many traditional crafts such as sewing, quilting and embroidery. Although Mod (2018) emphasized that waste cloths and fabrics that cannot be used in this way are selectively blended and used in the workplace for industrial and scientific processes such as filtering. Miscellaneous uses include flags, backpacks, tents, nets, handkerchiefs, cleaning rags, transportation devices such as ballons, kites, sails and parachutes. Fabrics are also used to provide strengthening in composite materials such as fibreglass and industrial geo-textiles (Anomie 2018). Fabrics that are regarded as wastes are usually compressed for mattress productions among other products (Mod (2018). They can also be used for making the comfortable padding in things like furniture. Mod (2018) added that some of the waste fabrics that can not be reused are recycled as rags or wiping cloths. These are handy in garages and various industrial areas for clean-ups.

Recycling of waste is defined as any recovery operation by which waste materials are reprocessed into products, materials or substances whether for the original or other purposes (Environment Glossary 2014). Fabric recycling is the process by which old clothing and other textiles are recovered for reuse or material recovery. Leblanc (2017) emphasized that it is the basis for the fabric recycling industry. Most factory fabric recycling involves the use of chemicals and machines in the dissolving of wasted fabrics to produce new fabrics, but in the present study there is need for direct physical use of wasted fabrics without applying any chemical processes to produce another product. This is usually achieved in clothing and fashion using different patch work techniques for the production of new clothing using these waste fabrics. That means fixing or joining different fabrics together to produce new clothing. These clothing can be human wears or covers for other surfaces.

\subsection{Statement of the Problem}

There are a lot of waste fabrics that litter Nigerian roads. Most of these fabrics are not easily biodegradable and so they form nuisance to the Nigerian environment. These fabrics have many sources, which include homes, industries and even form tailors shops. There is need to put these fabrics into other uses in order to improve the environment and even to improve the economics situation of the nation as some of the produced materials can be used by some individuals to earn a living.

\section{SOURCES OF WASTE FABRICS}

\section{Industrial Mistakes}

Industrial solid wastes are mostly non-hazardous solid wastes and include solid wastes generated by industrial processes and manufacturing (American Veterinary Medical Association 2018). Teracycle (2018) explained that post industrial factory wastes are wastes generated in a factory during the manufacturing process, often in the form of product scraps, trims, overruns, punch-outs, or other processing wastes; pre-consumer factory wastes are wastes generated in a factory from completed products, often in the form of misprint, defective, or excess products; postconsumer wastes are wastes generated after a product has been used and disposed of by the consumer. Postconsumer wastes are the type of wastes that people are most familiar with, as they mostly throw it in a garbage can or recycling bin. Leblanc (2017) explained that the necessary steps in the fabric recycling process involve the donation, collection, sorting and processing of fabrics and then subsequent transportation to end users of used garments, rags or other recovered materials. The recycling or reuse of factory fabric wastes offers the opportunity to return large volumes of waste to other uses.

\section{Pattern marker fallouts}

A pattern is a piece of paper drafted and cut to size and shape, used for cutting out fabric pieces for sewing out dresses (Igbo and lloeje 2003). Pattern layout is the way in which the parts of pattern are arranged on fabric while cutting fabrics. Comprehensive fabric reconciliation is essential in the cutting room. The measuring department determines the fabric yardage needed for each style and size of garment. Computer software helps the technicians create the optimum fabric layout to suggest so fabric can be used efficiently. Markers, made in accordance to the patterns are attached to the fabric with the help of adhesive stripping or staples. Markers are laid in such a way that minimum possible fabric gets wasted during cutting operation. In any cutting operation even with the use of patterns, pieces of fabrics are usually cut out and thrown away. These pieces of fabric are the fabrics that can be recycled or put to other uses in clothing and fashion. 


\section{Marker Making Fall Outs}

An essential step in the manufacture of clothing is the generation of a cutting plan or marker. The marker determines how the parts that made up an article of clothing are cut from a bolt of cloth. Automatic generation of markers would better enable manufacturers to keep up with customer demands for different styles and sizes. When there are wastage of fabrics during marking, it is referred to as marker fall outs. These fall outs are the pieces that can be recycled for other purposes.

\section{Remnants from free hand cutting}

Free hand cutting is a term used to refer to a tailor sewing without the use of patterns. When pattern templates are not used in the cutting of a garment, big fabric remnants are wasted after cutting. When patterns are properly used for cutting a garment, there will still be remnants of fabrics that will not be used but these are usually very small. Since there is no way a design of any garment can be cut from another fabric without having small pieces of fabric that will not be put to use. Fabric losses can occur in the cutting room due to remnants that can be left aside as the bulk of fabrics are being cut. Remnants are a small part of something that remains after the rest has gone. They are small amount of unsold cloth or flooring material left at the end of a roll of fabric, they are often sold at a reduced price since they are not enough to produce the required wears. Remnants are usually small in amount or a trace of fabrics which sometimes can not be entirely avoided in the cutting room.

\section{Old clothes from homes}

These days, people often live in a wasteful society. Mod (2018) pointed out that many homes end up disposing of a lot of waste clothes and fabrics even when they are perfectly reusable. The waste clothes and fabrics mainly come from households. These waste clothes and fabrics can be pieced and used to sew new clothing articles which can be reused again in these homes and outside these homes.

\section{Damaged products from factories}

Certain quality related problems, often seen in garment manufacturing like sewing, colour, sizing, or garment defects can never be over looked. Faults may exist in a completed product due to one or more of the following causes:- faulty raw materials, faulty machinery and faulty operative performance. General faults are, for example, those resulting from machine or operative defects, such as incorrect threading, careless handling, slipped stitches, bad tension and seam breaking away. Job faults are those which occur specifically in the job being studied. Damages can occur in the cutting room from wrong cutting of garments, this mostly happen if heaps of cloths are cut using the manual method. Sometimes too much heat on fabrics can cause physical injury to the fabric and that makes the fabric less useful, valuable, or unable to function for a particular purpose for which it is needed. Damages on fabrics are harmful effects on a bulk of fabric or on a piece of fabric. These damaged fabrics can be recycled or put to other uses.

\section{Spreading losses}

With the help of spreading machines, fabric is stacked on one another in reaches or lays that may go over $100 \mathrm{ft}$ $(30.5 \mathrm{~m})$ long and hundreds of plies (fabric pieces) thick. The fabric is then cut with the help of cloth cutting machines suitable for the type of the cloth. During the spreading process, cloth rolls can be unwound through several traditional ways. Custom-made roll stands are used in factories which are generally kept on the floor. This gives rise to displacement problems and with this there can be tilts also during sudden tension. At the Spreading stage fabric sheet is layered one above another maintaining pre-defined maker length and correct ply tension. Fabric is layered up to a certain height to avoid cutting quality problem. Spreading is done by manual layering or automatic layering machine can be used. During layering of the fabric, fabric edge is aligned at one side. When losses are encountered due to wrong spreading, they are called spreading losses. These fabrics from spreading losses are also referred to as wasted fabrics that can be put to other uses.

\section{Tailors mistakes}

Separated garment components are numbered to ensure that in stitching all components from the same layer are stitched together. When this is not properly done in sewing, the product becomes a mistake from the tailor and this is a form of fabric waste. Between the cutting and sewing processes, cut components may be passed through other processes like printing and embroidery. There is maximum chance of mixing of the components. If there is layer number in each component then at the time of stitching only correct components will be stitched together. If this is not properly done by the tailor, it becomes a mistake that leads to waste of fabrics. Open seams, wrong stitching techniques, non- matching threads, and missing stitches, improper creasing of the garment, erroneous thread tension and raw edges are some of the sewing defects which can affect the garment quality adversely and result to fabric wastes. During processing the quality control section needs to check each prepared article against these defects or else enough wasted fabric that will need recycling will result. 


\section{USES OF THESE WASTE FABRICS}

\section{Sewing new clothes}

These new clothes can be children's wears, men's wears, and women's wears. These wears are made using patch work techniques. When the fabrics are not heavily soiled or worn out, different wears can be made from such fabrics and it is usually difficult for people to be able to identify the difference between an old patched clothe and these new ones.

\section{Making bed sheets and quilts}

All the garments, bed linen, and other articles that are washed when doing the laundry are also clothing (Encarta 2009). Every bed needs basic bedding which includes bed linens, sheets, pillows, blankets, a mattress pad and a decorative cover such as a comforter, quilt, or duvet cover (Donahoe, Axelrod, Carges, Jacobson, Marks, Norrington, Swan, Thompson, and Tilenius 2009). That was why Graul, Cauley and Maehren (1991) stressed that sewings for the bed include duvet covers, bed skirts, and pillow shams to mention a few. Wasted fabrics can be used in producing these articles using different patched work designs.

\section{Making new bags}

There were also bags produced from pieces of different leathers patched together. These leathers could be picked from refuse dumps and yet most textile and clothing entrepreneurs make a lot of money from such products. Bags are another set of products that can be produced from cheap materials or wasted fabrics that are easily available in the Nigerian society.

\section{Making foot Wears}

The only consoling thing about shoe production it that all the materials used in the production of the shoes are readily available and easily affordable. Allen (2005) explained that some of these materials can even be picked from scrapes. Shoe production can therefore be said to be a small scale entrepreneurial establishment, according to Ikpe and Onwe (2007) small scale entrepreneurial establishments are in distributive trade and services, and being a small scale business it does not need much capital to be established. Wasted fabrics can be used for making different kinds of foot wears for individuals of different social status to wear them.

\section{ECONOMIC IMPORTANCE OF THESE ARTICLES FROM WASTE FABRICS}

\section{Profit making}

These articles can be a source of livelihood to different individuals in the society. Profits can be made from such products especially for the individuals in the small business sector. Mkhize (2006) explained that the small business sector has an important role to play in the development and growth of the economy. Ikpe and Onwe (2007) pointed out that small scale businesses are seen everywhere in any environment. With this, it evident that profits can be made from these products in any environment.

\section{Entrepreneurship training}

An entrepreneur, according to Samson and Little (1998), is a person who organizes and manages a business undertaking, assumes the risk of failure or gains the benefit of success in the business. An entrepreneur being an ambitious leader often have strong beliefs about a market opportunity and organizes the available resources effectively to accomplish an outcome that changes existing interactions (Wikipedia, 2008). Thus entrepreneurship, according to Ombugadu (2007), involves recognising a business opportunity, mobilizing resources and persisting to exploit that opportunity. Entrepreneurship is the self employment of any sort (Lavania 2004). While training potential entrepreneurs in clothing and fashion, these fabric wastes can be used, this will reduce the cost of the materials used for such trainings.

Production of Instructional materials - Instructional materials are those materials that help the teachers to teach with ease and the learners to learn without stress (Olumorin, Yusuf and Ajidagba 2013). They consist of all forms of information carriers, which can be used to promote and encourage effective learning in teaching activities. Olaitan, Nwachukwu, Onyemachi, Igbo and Ekong (1999) added that they can also be seen as the devices developed or acquired to assist vocational technical teachers in transmitting organized knowledge, skills and attitudes to learners within an instructional situation directed toward learning and acquisition of skills for work. Nwachukwu (2006) referred to instructional materials as training materials, explaining that training materials are those resources available for the teacher or instructor to help students to learn effectively. In clothing and fashion, wasted fabrics can be used in the production of different articles which can serve as instructional materials for training students in the classes. 


\section{Environmental sanitation}

Reuse of textiles and mechanised recycling methods ease the burden on the environment, the textile mass also includes material in poor condition or heavily soiled, limiting the opportunity for recycling (VTT Technical Research Centre of Finland 2014). Textile recycling saves virgin raw materials for products with higher production value and the prerequisite for functional recycling is a system that recovers textiles efficiently with regard to environmental considerations (VTT Technical Research Centre of Finland 2014). This is the major target of this study as the process of recycling in this situation does not involve any chemical process that can emit hazardous chemicals to the environment, rather the fabrics are reused for the production of new articles.

\section{CONCLUSIONS}

The recycling of wastes offers the opportunity to return large volumes of waste to fabric production. Articles as good as or better than the original can be obtained by reusing or recycling waste fabrics. Fabric recycling saves virgin raw materials for products with higher production value. Fabric production has often made use of rags, especially in times of shortage. Recycling waste fabrics is a very good way of converting waste to wealth in any given society. Fabric recycling can go a very long way in improving the economy of any nation and sanitizing the environment where these waste fabrics are usually dumped.

\section{RECOMMENDATIONS:}

Based on the study the following reccomendations are made:

1. Individuals in the Nigerian society should be discouraged from discarding used fabrics in the homes by exposing them to different ways of recycling these fabrics for further uses in the homes.

2. Government, schools and the mass media should make joint efforts at encouraging the public to recycle or reuse fabrics for other products than burning them which emits fumes that leads to air pollutions of the environment.

\section{REFERENCES}

1. Allen, A. (2005). Making Mid 19th Century Shoes. Retrieved on 15/7/2009 from http://www.thegracefullady.com/1860sShoes/

2. American Veterinary Medical Association (2018). Definitions: What is Waste?. Retrieved from https://www.avma.org on 11/2/2018.

3. Anomie B. O. T. (2018) in Wikipedia (2018). Textiles. Retrieved from http://en.m.wikipedia.ortg on 10/2/18

4. Clayton, N (2000). Young Living. New York: Glencoe and McGraw-Hill

5. Donahoe, J., Axelrod, B., Carges, M., Jacobson, M., Marks, A., Norrington, L., Swan, B., Thompson, S. and Tilenius, S. (2009). Bedding Buying Guide. Retrieved from http://pages.ebay.com/buy/guides /beddingbuying-guide/ on 16/7/2009

6. Environment Glossary (2014). Glossary: Recycling of waste. Retrieved from ec.europa.eu on 9/2/2018.

7. FCC Austria Abfall Service AG 2018. Clothes. Retrieved from www.fcc.group.eu. on 9/2/2018.

8. Graul, Z. A., Cauley, J. and Maehren, B. (1991). Sewing Projects for the Home. U.S.A.: Cy DeCosse Incorporated

9. Igbo, C. A. and lloeje, C. I. (2003). The Basics of Dress Pattern Drafting. Enugu: Inselberg Nigeria Ltd.

10. Ikpe, L. and Onwe, O. J. (2007). Small Business Management. Lagos: National Open University of Nigeria Victoria Island. Retrieved from www.nou.edu.ng on 2/7/2009

11. Lavania, G. A (2004). Entrepreneurship, Category: Business and Money. Retrieved from http://answers.google. com/answers/thread view/id/316327.html on 9/3/2009

12. Leblanc, R. (2017). The Basics of Textile Recycling. Retrieved from https://www.thebalance.com on 23/2/18

13. Microsoft Encarta (2009). Textiles. Microsoft Corporation 1993-2008.

14. Microsoft Encarta (2009). Clothing. Microsoft Corporation 1993-2008.

15. Mkhize, Z. (2006). MEC for Finance and Economic Development, at the Youth Economic Empowerment Summit 2006, presented at Ladysmith Indoor Sport Complex in Ladysmith. Issued by: Department of Finance and Economic Development, KwaZulu-Natal Provincial Government, South African Government Information. Retrievedfrom http://www.kwazulunatal.gov.za/ on 13/3/2009

16. Mod (2018). Clothes and Fabric Recycling. Retrieved from www.recycleaid.co.uk on 20/2/18

17. Nwachukwu, C. E. (2006). Designing appropriate methodology in vocational and technical education for Nigeria. Nsukka: University Trust

18. Olaitan, S. O., Nwachukwu, C. E., Onyemachi, G., Igbo, C. A., \& Ekong, A. O. (1999). Curriculum development and management in vocational technical education. Onitsha: Cape Publishers International 
19. Olumorin, C. O., Yusuf, A. \& Ajidagba, U. A. (2013). Development of instructional materials from local resources for art based courses. Retrieved from http://www.musero.org.ng/publications/DEVELOPMENTOFINSTR UCTIONAL-MATERIALS-FROM-LOCAL-RESOURCES-FOR-ART-BASEDCOURSES.pdf on $30 / 10 / 13$

20. Ombugadu, A. E. (2007). The Role of Home Economics in Developing Entrepreneurial Activities in Rural Areas of Nassarawa State: Journal of Home Economics Research (JHER) Vol. 8, p. 50-56.

21. Rouse, M. (2018). Recycling. Retrieved from whatis.techtarget.com on 9/2 2018.

22. Samson, H. E. and Little, W. G. (1998). Retail Merchandising: Consumer Goods and Services (10th Ed.). Ohio: South-Western Publishing Co.

23. Teracycle 2018. Recycling terms and definitions. Retrieved from http://www.terracycle.com on 9/2/2018.

24. VTT Technical Research Centre of Finland (2014). Textile waste can be made into Fabrics that are even better than the Original. Retrieved from https://m.phys.org on 23/2/18

25. Wikipedia (2008). Entrepreneur. Retrieved from http://en.wikip edia.org/wiki/Entrepreneur on 13/3/2009.

26. Wikipedia (2018). Recycling. Retrieved from http://en.m.wikipedia.org on 9/2/2018.

27. Wikipedia (2018). Wastes. Retrieved from https://en.m.wikipedia.org on 11/2/2018. 